\title{
Avaliação de alguns parâmetros físicos e químicos das águas dos igarapés Caxangá e Mirandinha na área urbana da cidade de Boa Vista, Roraima
}

\author{
Ivanise Maria Rizzatti ${ }^{1,2} \&$ Iury José Sodré Medeiros ${ }^{1}$
}

1. Universidade Estadual de Roraima, Programa de Pós-graduação em Ensino de Ciências. Rua Sete de Setembro, 231. Bairro Canarinho, CEP 69306-530, Boa Vista, Roraima, Brasil.

2 Autor para correspondência: rizzatti@uerr.edu.br.

Recebido em : 10/01/2013. Aceito em: 18/02/2013.

\section{RESUMO}

Este trabalho procura avaliar alguns parâmetros físico-químicos relacionados à qualidade das águas nos igarapés Caxangá e Mirandinha que deságuam no rio Branco e estão localizados no município de Boa Vista, Roraima. Foram escolhidos dois pontos para a realização das coletas, sendo o ponto 1, localizado no bairro Canarinho situado antes da captação de água da Estação de Tratamento de Água (ETA), e o ponto 2, no bairro Caetano Filho, localizado após a ETA do município de Boa Vista. Os parâmetros analisados nas amostras de água superficial in loco foram temperatura e potencial hidrogeniônico - $\mathrm{pH}$, sendo que no laboratório foram avaliados os parâmetros condutividade elétrica, sólidos totais dissolvidos, cloro total e turbidez. Comparando os resultados obtidos com os parâmetros de qualidade dispostos na Resolução $n^{\circ}$ 357/2005 do CONAMA, os valores de condutividade elétrica e turdidez estavam acima do valor, devido provavelmente ao processo de urbanização desordenada que está afetando a qualidade da água destes igarapés.

PALAVRAS-CHAVE: Água, Igarapé, Qualidade.

\section{ABSTRACT}

This paper seeks to evaluate some physicochemical parameters related to water quality in streams Mirandinha and Caxangá that drain into the White river and located in the city of Boa Vista, Roraima. Two points were chosen to perform the collection, and point 1 , located in the neighborhood Canarinho located before the water catchment of the Water Treatment Plant (WTP), and point 2 in the neighborhood Caetano Filho, located in the city after the WTP Boa Vista. The parameters analyzed in samples of surface water on site were temperature and hydrogenic potential - $\mathrm{pH}$, and laboratory parameters were measured electrical conductivity, total dissolved solids, total chlorine and turbidity. Comparing the results with the quality parameters laid out in Resolution No. $357 / 2005$ of CONAMA, the values of electrical conductivity and turdidez were above the value, probably due to unplanned urbanization process that is affecting the water quality of streams.

KEYWORDS: Water, streams, Quality.

\section{INTRODUÇÃO}

A região norte do país é conhecida mundialmente pela abundância em água doce, principalmente pelos extensos rios que cortam a região amazônica. Com o grande crescimento da região e, principalmente, pela devastação da área amazônica, seja pelo avanço da agropecuária ou crescimento populacional, a região está sofrendo grande impacto no que diz respeito à poluição de suas águas, incluindo rios e igarapés, principalmente os localizados dentro ou próximos de regiões populosas, onde o tratamento de esgoto, infelizmente não está disponível para todos, sendo lançado diretamente em rios sem nenhum tratamento prévio.

O Estado de Roraima apresenta um rico acervo hidrográfico, ainda pouco pesquisado, e localiza-se em forma de uma cunha entre a Guiana (a leste e norte) e a Venezuela (a norte e oeste), possuindo uma área de $225.116,1 \mathrm{~km}^{2}$. A capital Boa Vista, criada em 1890, ocupa uma área de $5.687 .022 \mathrm{~km}^{2}$ onde vivem aproximadamente cerca de 284.313 habitantes, correspondendo a $63,11 \%$ da população roraimense (IBGE 2010), é cortada por rios e vários igarapés, constituindo refrescantes $\mathrm{e}$ lindos pontos turísticos (Freitas 2009).

Entretanto, com o aumento da população na capital, novos bairros vão sendo criados, muito deles em áreas de proteção permanente, às margens dos igarapés. Com isso, populares não têm a preocupação de conservá-los, esquecendo que a água é uma substância indispensável para a vida.

Aliado a isto, o abastecimento de água da capital ocorre através da captação superficial das águas do rio Branco, tendo como principal afluente o rio Cauamé. Dentre os igarapés, o Mirandinha e o Grande são considerados os dois afluentes principais do rio Branco na área 
urbana do município de Boa Vista.

Apesar de Boa Vista ser uma capital planejada, grande parte do esgoto doméstico é lançado diretamente nos igarapés, poluindo de maneira drástica esses pontos de banho. Através da preocupação com a qualidade e tendo em vista que todas as formas de vida existentes na Terra dependem da água e, que a cada dia a disponibilidade de águas naturais para o consumo humano no planeta está diminuindo, torna-se de fundamental importância a análise e monitoramento da qualidade dos recursos hídricos (Okura \& Siqueira 2005; Neto et al. 2006).

A poluição das águas é fruto, principalmente, de um conjunto de atividades humanas. A destinação incorreta de dejetos de animais e humanos pode provocar a contaminação dos mananciais e possivelmente a disseminação de enfermidades como cólera, febre tifóide, hepatite A e outras doenças diarréicas agudas (FUNASA 2002).

De maneira análoga à maioria das cidades que crescem às margens dos rios, observa-se claramente em Boa Vista o impacto antrópico gerado nas microbacias, uma vez que a ocupação humana em área de lagoas, alagados e margens de rios e igarapés traz grande degradação e agressão ao meio ambiente. Dentre os igarapés afetados por esses problemas dentro da área urbana de Boa Vista, pode-se citar o igarapé Caxangá, que tem suas margens ocupadas por moradores e o igarapé Mirandinha, que além de suas margens estarem ocupadas e degradadas, ainda está sofrendo processo de canalização, piorando ainda mais a situação da qualidade de suas águas. Vale lembrar que estes dois igarapés deságuam no rio Branco onde é captada a água para o consumo da população.

De acordo com Bueno (1968), a palavra igarapé deriva do tupi "igara", que significa "aberta; passagem de canoas entre as vegetações aquáticas" e "pé”, "caminho". Segundo Ferreira (1993) este também é um termo utilizado na Amazônia brasileira para definir um pequeno rio, às vezes navegável. No período de precipitação, alguns desses igarapés formam áreas alagadas (várzeas), com volume, correnteza e extensão que, em outros estados brasileiros, podem ser confundidos com rios.

Considerando que todas as formas de vida existentes na Terra dependem da água e, que a cada dia a disponibilidade de águas naturais para o consumo humano no planeta está diminuindo, torna-se de fundamental importância a análise e monitoramento da qualidade dos recursos hídricos.

Este trabalho teve como intuito avaliar alguns parâmetros físicos e químicos, relacionados à qualidade das águas nos Igarapés Caxangá e Mirandinha, em dois pontos próximos ao rio Branco localizados na área urbana do município de Boa Vista, Roraima, procurando contribuir, assim, para o acervo de informações sobre os recursos hídricos de Roraima, proporcionando a verificação das condições do efeito da urbanização sobre a qualidade dos corpos d'água.

O monitoramento da qualidade da água, além de registrar as variações espaçotemporais, relaciona os diversos mecanismos do sistema hídrico com toda a sua bacia de drenagem, a exemplo da capacidade de autodepuração (Jong et al. 1995).

Desta forma, o conhecimento científico dos rios e igarapés como ecossistemas, suas interações com as bacias hidrográficas e com os sistemas a montante e jusante, tem adicionado permanentemente novas dimensões à abordagem sistêmica na pesquisa ecológica, proporcionando uma base fundamental para o gerenciamento da qualidade da água e das bacias hidrográficas.

\section{MATERIAL E MÉTODOS}

Para a realização deste trabalho inicialmente fez-se uma pesquisa bibliográfica sobre o assunto e depois foi feito um trabalho de campo para reconhecimento da área de estudo e para coleta das amostras.

\section{Delimitação da área de estudo}

Para avaliar as implicações e efeitos da ocupação urbana sobre a qualidade das águas dos igarapés Caxangá e Mirandinha que deságuam no rio Branco, principal fonte de água potável da população de Boa Vista, foram selecionados dois pontos de amostragem dentro da área urbana da capital Roraimense, um em cada igarapé estudado. A Figura 1 apresenta a localização dos pontos selecionados nos igarapés acima citados.

Os pontos foram georreferenciados, o ponto 1 apresentou as coordenadas geográficas: latitude $02^{\circ} 50,29^{\prime} \mathrm{N}$, longitude $06^{\circ} 39,17^{\prime} \mathrm{W}$, e o ponto 2 situou-se na latitude $02^{\circ} 48,66^{\prime} \mathrm{N}$ e 
longitude $06^{\circ} 40,26^{\prime} \mathrm{W}$.

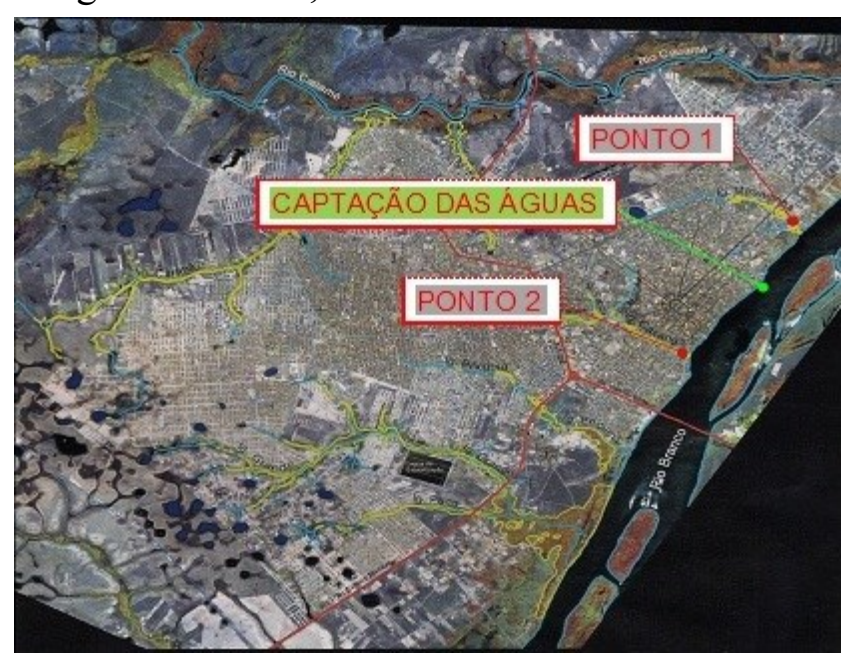

Figura 1. Localização geográfica do pontos 1 (a) e 2 (b) nos igarapés Mirandinha e Caxanga, respectivamente, onde foram realizadas as coletas de água para análise.

\section{Coleta das amostras e Amostragem}

As amostras de águas superficiais foram coletadas a aproximadamente $20 \mathrm{~cm}$ de profundidade, emergindo contra corrente, após foram transferidas para garrafas PET, previamente limpas e identificadas com as seguintes informações: ponto de amostragem, local, data e horário da coleta. Os frascos com as amostras foram preservados em caixa de isopor.

As coletas foram realizadas durante três dias no mês de julho de 2011, no período da manhã (Tabela 1), seguindo as normas estabelecidas pelo Laboratório de Turismo, Ecologia e Meio Ambiente da Universidade Estadual de Roraima (LabTEMA). O ponto 1 foi coletado no igarapé Mirandinha, na parte baixa logo após a Avenida Getúlio Vargas, no bairro Canarinho, e o ponto 2, no igarapé Caxangá, antes da ponte localizada no Bairro Caetano Filho (Beiral).

Tabela 1: Dados sobre data e horário das coletas nos igarapés Mirandinha (ponto 1) e Caxangá (ponto 2).

\begin{tabular}{|l|l|l|}
\hline \multirow{2}{*}{ Pontos } & \multicolumn{2}{|c|}{ Coleta } \\
\cline { 2 - 3 } & \multicolumn{1}{|c|}{ Data } & \multicolumn{1}{c|}{ Horário } \\
\hline 1 & $02 / 07 / 11$ & $7 \mathrm{~h}$ \\
\hline 2 & $02 / 07 / 11$ & $7 \mathrm{~h}$ e $15 \mathrm{~min}$ \\
\hline 1 & $04 / 07 / 11$ & $6 \mathrm{~h}$ e $44 \mathrm{~min}$ \\
\hline 2 & $04 / 07 / 11$ & $7 \mathrm{~h}$ e $5 \mathrm{~min}$ \\
\hline 1 & $05 / 07 / 11$ & $6 \mathrm{~h}$ e $42 \mathrm{~min}$ \\
\hline 2 & $05 / 07 / 11$ & $7 \mathrm{~h}$ e $2 \mathrm{~min}$ \\
\hline
\end{tabular}

\section{Análise Física e Química}

Nas amostras coletadas foram determinados parâmetros como temperatura, $\mathrm{pH}$,

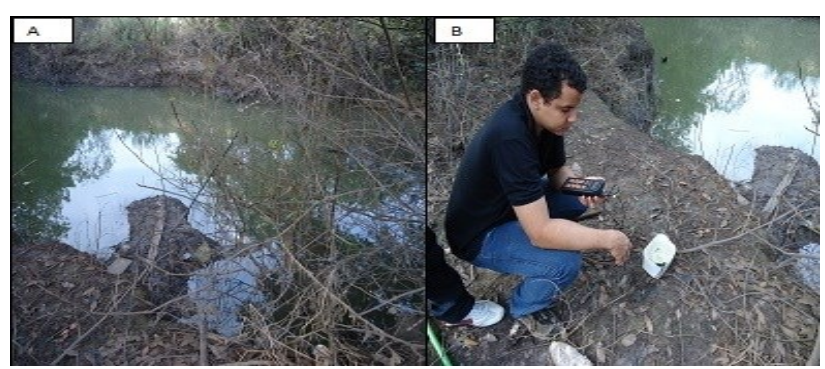

Figura 2. Local de coleta no igarapé Mirandinha (A) e medida in loco do $\mathrm{pH}$ e temperatura na amostra coletada (B).

condutividade elétrica, turbidez, sólidos totais e cloretos.

As medidas de temperatura e $\mathrm{pH}$ foram realizados in loco (Figura 2) utilizando um $\mathrm{pHmetro/ORP/Temperatura} \mathrm{digital} \mathrm{portátil}$ modelo HI8424 da marca HANNA. Os demais parâmetros foram analisados no Laboratório de Turismo, Ecologia e Meio Ambiente (LabTEMA), contudo, para reduzir-se ao máximo a volatilização ou a biodegradação da amostra entre o momento de coleta e o de análise, as amostras foram mantidas em geladeira para posterior medição de cloro total e turbidez.

As análises de condutividade elétrica e sólidos totais dissolvidos foram realizadas em um condutivímetro portátil modelo HI9835N, cloro total em um fotômetro modelo HI 96711C e turbidez em um turbidímetro portátil digital modelo HI 98703-02 todos da marca HANNA.

Os equipamentos utilizados eventualmente para a coleta das amostras foram previamente lavados com o próprio líquido a ser coletado, e depois da leitura foram lavados com água destilada.

O ponto 2 foi coletado no bairro Caetano Filho localizado após a estação de tratamento de água (ETA) também do município de Boa Vista-RR, a Figura 3 apresenta o local e como foi coletada as amostras de água superficial.

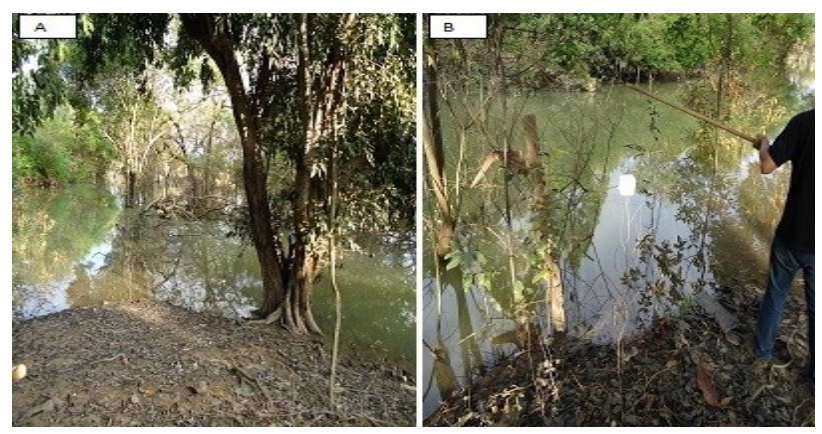

Figura 3. Local de coleta no igarapé Caxangá (A) e procedimento de coleta das amostras de água superficial (B). 


\section{RESULTADOS E DISCUSSÃO}

Os resultados obtidos para os parâmetros avaliados nas amostras coletadas nos igarapés Mirandinha (ponto 1) e Caxangá (ponto 2) são apresentados na tabela 2 .

Os valores padrões estabelecidos pela Resolução do CONAMA n ${ }^{\circ} 357 / 2005$ estão apresentados na Tabela 3. Apesar de somente ter sido realizado a análise em 3 dias consecutivos e por um período curto é possível fazer algumas observações sobre a qualidade das águas destes igarapés, levando-se em consideração os resultados obtidos para os parâmetros físico-químicos analisados e comparados com os estabelecidos pela resolução do CONAMA n 357/2005.

Nas coletas realizadas no dia 02/07/11 nos dois pontos avaliados os valores de turbidez mostraram-se acima do limite máximo estabelecido pela resolução do CONAMA ${ }^{\circ}$ $357 / 2005$, demonstrando o reflexo da proliferação da urbanização desordenada e destruição da mata ciliar nestas áreas. Nos dias 4 e 5/07/11 os valores não ultrapassaram esses limites, vale ressaltar que no dia 3/07/11 houve a ocorrência de chuvas que podem ter influenciado nos valores de turbidez.

A turbidez representa o grau de interferência à passagem da luz através da água, conferindo uma aparência turva à mesma. A alta turbidez reduz a fotossíntese de vegetação enraizada submersa e algas. $\mathrm{O}$ desenvolvimento reduzido de plantas pode, por sua vez, suprimir a produtividade de peixes. Logo, a turbidez pode influenciar nas comunidades biológicas aquáticas.

Segundo Oliveira-Filho et al. (1994), a devastação das matas ciliares tem contribuído para o assoreamento, o aumento da turbidez das águas, o desequilíbrio do regime das cheias, a erosão das margens de grande número de cursos d'água, além do comprometimento da fauna silvestre. Arcova \& Cicco (1997) salientam que, nas microbacias de uso agrícola, quando comparadas às de uso florestal, o

Tabela 2. Valores obtidos para os parâmetros avaliados nas amostras de água superficial coletadas nos igarapés Mirandinha (ponto 1) e Caxangá (ponto 2). STD*: Sólidos Totais Dissolvidos.

\begin{tabular}{|c|l|l|l|l|l|l|}
\hline & \multicolumn{2}{|c|}{ Coleta dia 02/07/11 } & \multicolumn{1}{c|}{ Coleta dia 04/07/11 } & \multicolumn{2}{c|}{ Coleta dia 05/07/11 } \\
\hline Parâmetros & Ponto 1 & \multicolumn{1}{c|}{ Ponto 2 } & Ponto 1 & \multicolumn{1}{c|}{ Ponto 2 } & \multicolumn{1}{c|}{ Ponto 1 } & Ponto 2 \\
\hline Hora da Coleta & $7 \mathrm{~h}$ & $7 \mathrm{~h}$ e 15min & $6 \mathrm{~h}$ e 44min & $7 \mathrm{~h}$ e $5 \mathrm{~min}$ & $6 \mathrm{~h}$ e $42 \mathrm{~min}$ & $7 \mathrm{~h}$ e 2min \\
\hline $\mathrm{T},{ }^{\circ} \mathrm{C}$ & 27,8 & 28 & 28,4 & 28,6 & 27,9 & 28,2 \\
\hline $\mathrm{pH}$ & 6,32 & 6,54 & 6,24 & 6,50 & 6,32 & 6,50 \\
\hline Turbidez, NTU & 101,00 & 111,00 & 90,00 & 100,00 & 85,00 & 90,00 \\
\hline $\begin{array}{c}\text { Cloro Total, } \\
\mathrm{mg} / \mathrm{L}\end{array}$ & 0,02 & 0,00 & 0,02 & 0,00 & 0,00 & 0,00 \\
\hline $\begin{array}{c}\text { Condutividade } \\
\text { Elétrica, } \mu \mathrm{SS}\end{array}$ & 111,70 & 136,00 & 92,80 & 113,90 & 93,60 & 100,60 \\
\hline \begin{tabular}{c} 
STD*, mg/L \\
\hline
\end{tabular} & 55,90 & 68,00 & 46,40 & 56,90 & 46,80 & 50,30 \\
\hline
\end{tabular}

Tabela 3. Valores de referência para os parâmetros analisados segundo a Resolução do CONAMA n $357 / 2005$. STD*: Sólidos Totais Dissolvidos.

\begin{tabular}{|c|c|c|c|c|c|c|}
\hline Parâmetros & $\mathrm{T},{ }^{\circ} \mathrm{C}$ & $\mathrm{pH}$ & $\begin{array}{c}\text { Turbidez, } \\
\text { NTU }\end{array}$ & $\begin{array}{c}\text { Cloro Total, } \\
\mathrm{mg} . \mathrm{L}^{-1}\end{array}$ & $\begin{array}{c}\text { Condutividade } \\
\text { Elétrica, } \mu \mathrm{S}\end{array}$ & $\begin{array}{c}\text { STD*, } \\
\mathrm{mg} / \mathrm{L}\end{array}$ \\
\hline $\begin{array}{c}\text { Valores de } \\
\text { referência }\end{array}$ & - & 6,0 a 9,0 & Até 100 & Até 250 & & Até 500 \\
\hline
\end{tabular}


transporte de sedimentos e a perda de nutrientes são maiores.

$\mathrm{O}$ pH é uma função da proporção entre os íons $\mathrm{H}^{+}$e $\mathrm{OH}^{-}$, em solução. Essa propriedade tem influência sobre a fisiologia dos seres aquáticos, sobre a permeabilidade das membranas vivas e sobre a qualidade da água. É um parâmetro que deve ser sempre avaliado, pois pode interferir no processo de coagulaçãoprecipitação química durante o tratamento da água, na corrosão de tubulações e equipamentos, no crescimento microbiano dos sistemas biológicos de tratamento, na toxidez de certos compostos e nos constituintes da alcalinidade e acidez da água.

A influência do $\mathrm{pH}$ sobre os ecossistemas aquáticos naturais dá-se diretamente devido a seus efeitos sobre a fisiologia das diversas espécies (CETESB 2007). Os valores observados após análise das águas nos dias 2,4 e 5/07/11 dos igarapés Caxangá e Mirandinha se mostrou dentro dos limites estabelecidos pela resolução do CONAMA n ${ }^{\circ} 357 / 2005$.

Os Sólidos Totais Dissolvidos (STD) são importantes porque dão idéia da taxa de desgaste das rochas por intemperismo das áreas com elevados índices pluviométricos, das características litológicas da região através de íons presentes na água e da salinidade no meio. Os STD também servem para indicar se a água é doce $(0-500 \mathrm{mg} / \mathrm{L})$, salobra $(500-1500 \mathrm{mg} / \mathrm{L})$ ou salina $(>1500 \mathrm{mg} / \mathrm{L})$, de acordo com Lima \& Garcia (2008). Os resultados obtidos relativos aos sólidos totais dissolvidos nos igarapés Caxangá e Mirandinha encontram-se dentro dos padrões estabelecidos pela resolução do CONAMA n ${ }^{\circ} 357 / 2005$.

Os valores de cloro encontrados nos igarapés Caxangá e Mirandinha estão abaixo do estabelecido pela Resolução CONAMA n ${ }^{\circ}$ 357/05 para Águas Doces Classe 1 (250 mg/L).

A determinação da condutividade é um dos meios mais utilizados para quantificação da salinidade. Esta é a concentração total de íons dissolvidos e, assim sendo, pode-se dizer que a salinidade e os sólidos totais dissolvidos apresentam a mesma magnitude na maioria das águas. Observa-se que a condutividade elétrica está um pouco elevada nas amostras coletadas nos presentes igarapés, apesar de não ser possível determinar os íons diretamente responsáveis pelos valores da condutividade, é possível reconhecer que este índice um pouco elevado é resultante de esgoto descartado nesses igarapés observando, assim, que as águas desses locais já estão sofrendo impacto ambiental gerado pelos moradores da região.

A temperatura tem importância determinante sobre a densidade, viscosidade e movimentos de convecção da água. Também tem influência sobre vários processos biológicos, distribuição, periodicidade e reprodução dos organismos, reações químicas e bioquímicas que ocorrem na água. Pode-se observar na tabela 2 que a temperatura da água apresenta-se em condições normais nos dois pontos de análise, estando em compatibilidade com a realidade climática da região norte.

Durante as coletas observou-se que tanto o igarapé Caxangá quanto o Mirandinha estão sofrendo agressões visíveis quanto a qualidade de suas águas. Nos pontos de coleta foi possível observar a presença de lixo e a ausência de mata ciliar nos igarapés Mirandinha (ponto 1) e Caxangá (ponto 2), conforme é mostrado na Figura $4 \mathrm{~A}$ e B, respectivamente.

O Igarapé Caxangá, localizado no Bairro Caetano Filho, surge do encontro de outros dois pequenos igarapés, mas estes já vêm poluídos, oriundo de esgoto doméstico e despejo de lixo. No período chuvoso com a alta do rio Branco, o Caxangá também aumenta o seu nível e invade casas, carregando também grande quantidade de lixo, já no período seco, o igarapé está mais "limpo", sem tanto odor e

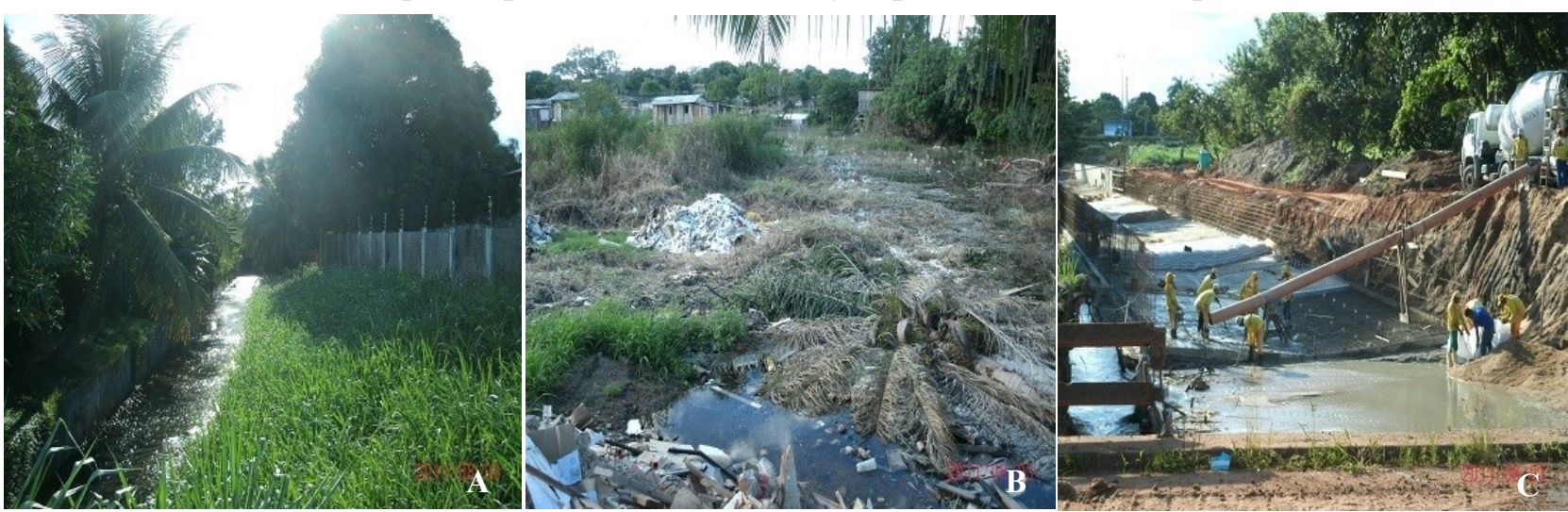

Figura 4. Agressões ambientais nos igarapés Mirandinha e Caxangá, Boa Vista. A:ausência de mata ciliar e parte da canalização do igarapé Mirandinha. B. Lixo no igarapé Caxangá. C. Canalização do igarapé Caxangá. 
sujeira, como na estação anterior. Porém, nesse período a mata ciliar do lado esquerdo é retirada e queimada. Desta forma, as margens do Caxangá não são lugares aconselháveis para habitação, já que há um nível muito alto de contaminação e as crianças brincam nas proximidades do igarapé, correndo assim muitos riscos à saúde. A Figura $4 \mathrm{C}$ mostra o processo de canalização do igarapé Caxangá ao longo de seu trecho.

O igarapé Mirandinha, que nasce no lago Americano, localizado dentro da área do Parque Anauá, tem seu percurso todo dentro da área urbana de Boa Vista, que além de sofrer todo o processo de degradação ambiental pela ocupação irregular de suas margens e lançamento direto de esgoto em suas águas, está passando por um processo de canalização, piorando ainda mais a sua situação em termos de qualidade de água e sobrevivência do igarapé. No processo de canalizar, tubular e retilinizar os igarapés, a revitalização destes ambientes torna-se mínima ou em alguns casos, impossível.

\section{CONCLUSÃO}

Tendo-se em vista que todos os seres vivos, assim como a maior parte dos ecossistemas terrestres, necessitam de água doce para sua sobrevivência, a preservação das fontes naturais hídricas é de suma importância para a existência da vida no planeta Terra.

Em relação à qualidade hídrica dos igarapés Caxangá e Mirandinha, de acordo com os resultados dos parâmetros físico-químicos obtidos no presente estudo, pode-se dizer que sua água é imprópria para balneabilidade e consumo humano quando se observa os parâmetros de turbidez e condutividade elétrica.

Apesar de Roraima possuir uma disponibilidade de água de $1.747 .010 \mathrm{~m}^{3} / \mathrm{hab} /$ ano sendo praticamente um dilúvio comparando-se aos demais estados Brasileiros, é necessário o comprometimento com a preservação dos recursos hídricos locais promovendo atos de fiscalização e educação ambiental com o intuito de coibir os danos ambientais.

Pode-se concluir que a sustentabilidade ambiental na região encontra-se comprometida devido aos problemas de poluição hídrica nos dois igarapés estudados, afetando diretamente a saúde da população, pois as águas oriundas destes igarapés deságuam no Rio Branco, principal fonte de abastecimento da população de Boa Vista, capital de Roraima. A geração de dados atuais, um dos produtos desse trabalho, foi útil para caracterizar a real situação da qualidade hídrica, definindo suas fontes de poluição e contaminação.

Todas essas informações serão úteis para ajudar no planejamento das intervenções de órgãos de vigilância ambiental e ao acervo de informações hídricas do estado de Roraima, contribuindo para a redução dos riscos à saúde e ao meio ambiente decorrente da poluição assegurando, assim, a atual e as futuras gerações a necessária disponibilidade de água, visando o desenvolvimento sustentável.

\section{AGRADECIMENTOS}

A Universidade Estadual de Roraima (UERR), ao Programa de Pós-graduação em Ensino de Ciências (PPGEC), ao Laboratório de Turismo, Ecologia e Meio Ambiente (LabTEMA) e ao Conselho Nacional de Desenvolvimento, Científico e Tecnológico (CNPq).

\section{REFERÊNCIAS BIBLIOGRÁFICAS}

Arcova, F. C. S. \& Cicco, V. 1997. Características do deflúvio de duas microbacias hidrográficas no Laboratório de Hidrologia Florestal Walter Emmerich, Cunha - SP. Revista do Instituto Florestal 9(2): 153-170.

Bueno, F. S. 1968. Grande Dicionário Etimológico Prosódico da Língua Portuguesa. São Paulo, $2^{\mathrm{a}}$ ed., Ed. Saraiva, vol 4: 1497-2059.

CETESB. 2013. Variáveis de qualidade das águas. Disponível em: <http://www.cetesb.org.br $>$. Acesso em: 13/02/2013.

Ferreira, A. B. H. 1993. Minidicionário da língua portuguesa. $3^{\text {a }}$ ed., Rio de Janeiro, Nova Fronteira.

Freitas, S. S. de. 2009. Eutrofização no reservatório Marcela em Itabaiana-SE e sua Implicações Ambientais. Monografia de Especialização em Gestão de Recursos Hídricos. Universidade Federal Fluminense, UFS.

Funasa- Fundação Nacional de Saúde. 2002. Guia de vigilância epidemiológica. 5 ed. Ver. Ampl. Brasília; Ministério da Saúde. 842p.

IBGE- Instituto Brasileiro de Geografia e Estatística. 2010. Página do Censo de 2010. Roraima, IBGE. Disponível em: http://www.censo2010.ibge.gov.br/ index. Php. Acesso em 13/02/2013.

Jong, J.; Rooy, P. T. J. C. \& Hosper, S. H. 1995. Living 
with water: at the crossroads of change. Water Science Technology 31(8): 393-400.

Lima, W. S.; Garcia, A. B. 2008. Qualidade da água em Ribeirópolis-SE: o açude do cajueiro e a barragem do João Ferreira. Dissertação de Mestrado, Universidade Federal Fluminense, UFS.

Neto, A. F.; Silva, J. L.; Moura, G. J. B.; Calazans, G. M. T. 2006. Avaliação da qualidade da água potável de escolas públicas do Recife, PE. Revista Higiene Alimentar 20 (139): 80-82.

Okura, M. H. \& Siqueira, K. B. 2005. Enumeração de coliformes totais e coliformes termotolerantes em água de abastecimento e de minas. Revista Higiene Alimentar 19 (135): 86-91.

Oliveira-Filho, A.T.; Almeida, R.J. de; Mello, J.M. de \& Gavilanes, M.L. 1994. Estrutura fitossociológica e variáveis ambientais em um trecho de mata ciliar do córrego Vilas Boas, Reserva Biológica do Poço Bonito, Lavras (MG). Revista Brasileira de Botânica 17(1): 67-85. 